\title{
Dissociating familiarity from recollection in human recognition memory: Different rates of forgetting over short retention intervals
}

\author{
ANDREW P. YONELINAS and BENJAMIN J. LEVY \\ University of Califormia, Davis, California
}

\begin{abstract}
Two functionally distinct forms of recognition memory have been identified in human and nonhuman species - the ability to recollect qualitative information about previous events, and the ability to differentiate between familiar and novel stimuli. Separate dual-process theories have been developed in the animal and human literatures to account for these findings. However, it is not clear whether these theories describe the same two underlying memory processes. On the basis of animal studies of medial temporal lobe function, familiarity is expected to exhibit disproportionately fast forgetting compared with recollection over short retention intervals. We tested this prediction in healthy human subjects by examining recognition forgetting rates across a range of 8-32 intervening items and found significant forgetting in the accuracy of familiarity-baseddiscriminations and no evidence of forgetting in the accuracy of recollection-based discriminations. In agreement with the results from nonhuman species, the present results indicate that item familiarity decreases more rapidly than recollection over short retention intervals.
\end{abstract}

A primary goal of memory research is to identify and characterize the different processes that underlie successful memory retrieval. Results from studies of human subjects indicate that two separate processes, or types of memory, support recognition memory judgments: familiarity and recollection. The familiarity process reflects the assessment of the memory strength or experimental familiarity of a test item. Because recently encountered items are more familiar than novel items, subjects can accept the more familiar items as having been studied. Recognition memory judgments, however, are not limited to assessments of familiarity. If a subject can recollect some associative information about the study episode, such as when or where the item was presented, this can also serve as a basis for recognition judgments. The distinction between recollection and familiarity underlies several contemporary theories of human memory (e.g., Atkinson \& Juola, 1974; Jacoby, 1991; Jacoby \& Dallas, 1981; Mandler, 1980; Tulving, 1985; Yonelinas, 1994), it has played a critical role in characterizing memory impaired populations, such as amnesics (e.g., Aggleton \& Shaw, 1996; Huppert \& Piercy, 1976; Yonelinas, Kroll, Dobbins, Lazzara, \& Knight, 1998), and it has proven useful in accounting for results from recent neuroimaging (e.g., Eldridge, Knowlton, Furmanski, Bookheimer, \& Engel, 2000; Gabrieli, Brewer, Desmond, \& Glover,

This work was supported by National Institute of Mental Health Grant MH59352-01. Correspondence should be sent to A. Yonelinas, Department of Psychology, University of California, Davis, CA 95616 (e-mail: apyonelinas@ucdavis.edu).
1997; Henson, Rugg, Shallice, Josephs, \& Dolan, 1999; Yonelinas, Hopfinger, Buonocore, Kroll, \& Baynes, 2001) and electrophysiological studies of memory (Curran, 2000; Düzel, Yonelinas, Mangun, Heinze, \& Tulving, 1997; Klimesch et al., 2001; Smith, 1993).

A similar distinction has also proven useful in accounting for memory performance in rats and nonhuman primates (for reviews see Aggleton \& Brown, 1999; Eichenbaum, Otto, \& Cohen, 1994; Rolls, 1996). For example, damage to the hippocampal region leads to a selective deficit on memory tests that require memory for associations between different aspects of a prior event, whereas lesions to the parahippocampal region (i.e., entorhinal, perirhinal, and parahippocampal corticies) disrupt performance on tests that require the discrimination between familiar and novel items (e.g., Gaffan \& Murray, 1992; Mishkin \& Murray, 1994; O'Keefe \& Nadel, 1978; but see Zola et al., 2000). These two types of tests might rely differentially on recollection and familiarity processes, respectively. Moreover, cells in the hippocampal and parahippocampal regions have been identified that could support recollectionand familiarity-based memory judgments. For example, the hippocampal region contains cells that code for specific spatial locations and object-space associations (e.g., Eichenbaum \& Cohen, 1988; O'Keefe, 1976), and these cells can maintain this information over a long time period. In contrast, recency cells have been identified in the parahippocampal region that are less responsive to specific stimuli when they are presented a second time (e.g., Brown, Wilson, \& Riches, 1987; Fahy, Riches, \& Brown, 1993). Importantly, this sensitivity to experimental familiarity decreases rapidly after an item is first presented, 
suggesting that the parahippocampal region does not support the type of long-term memory that is associated with the hippocampal region. However, it should be noted that the parahippocampal region can maintain familiarity information even after more than 20 intervening items have been presented, showing that it is distinct from working memory, which can maintain only a few items at a time (see Fahy et al., 1993).

Although there are parallels between the results from the human and nonhuman studies, it is not yet known whether the same two processes have been identified in these different species. In the present study, we do not aim to determine whether human and nonhuman memory processes are identical, but we do aim to take a preliminary step toward bridging the gap between the animal and human recognition memory literatures, by determining whether the animal results, and the theories that are based on those results, are useful in generating accurate predictions about the memory behavior of healthy human subjects. The nonhuman animal studies discussed above suggest that parahippocampal-dependent memory processes may be disproportionately sensitive to the effects of forgetting over short retention intervals compared with hippocampal-dependent processes. In fact, Eichenbaum et al. (1994) proposed a model of the medial temporal lobes that assumes that the parahippocampal region supports a form of intermediate term memory that decreases more rapidly than hippocampal-dependentmemory. If recollection and familiarity in humans are related to the hippocampal and parahippocampal memory processes observed in nonhuman species, familiarity, compared with recollection, should be particularly susceptible to the effects of forgetting over these retention intervals. If this prediction is verified, it would provide support for the Eichenbaum et al. (1994) model, and it would serve to bridge the animal and human literatures on recognition memory.

Our examining the effects of forgetting on recollection and familiarity will also be useful in characterizing these processes in humans, because the forgetting functions of recollection and familiarity in humans have not been directly compared. There are several studies that have examined forgetting rates in tasks that may be related to recollection and familiarity, but the results from those studies are mixed. For example, Mandler (1980; Mandler, Pearlstone, \& Koopmans, 1969) required subjects to sort words into a number of categories of their own choosing, then they were given recognition or recall tests after delays ranging up to 5 weeks. Recall performance across all delays was correlated with the number of categories that the subjects sorted items into during study, indicating that the recollection process supporting recall was sensitive to list organization. In contrast, recognition performance was not strongly correlated with list organization at the immediate test, but the correlation increased as the delay increased. The results were taken to be an indication that immediate recognition performance was dominated by familiarity-based responses that were not sensitive to list organization, whereas delayed recognition performance was dominated primarily by recollection-based responses that were sensitive to list organization. The fact that the correlation between recognition and list organization increased across delays suggests that the contribution of familiarity to performance decreases more rapidly than does recollection. In a more recent study, the ability to discriminate between studied word pairs and mixed word pairs remained constant across delay, whereas the ability to discriminate between studied and nonstudied items decreased (Hockley, 1991). If single word recognition relies more on familiarity than word-pair recognition, the results would suggest that familiarity is more susceptible to forgetting than is recollection. However, other studies indicate that recollection and familiarity are equally susceptible to forgetting. For example, studies contrasting item and source memory indicate that the ability to discriminate between items that were originally spoken by a male or female decreased at the same rate as the ability to discriminate between studied and nonstudied items (e.g., Bornstein \& LeCompte, 1995). If source recognition and item recognition are used as rough indexes of recollection and familiarity, the results would suggest that both processes are equally susceptible to forgetting. Studies in which the rememberknow procedure has been used (Tulving, 1985), in which subjects are instructed to report when their recognition responses are based on recollection or when they are based on familiarity in the absence of recollection, have led to mixed results regarding the effects of forgetting. In general, remember responses decrease over time, whereas know responses sometimes decrease, sometimes remain constant, and sometimes increase over time (Gardiner, 1988; Gardiner \& Java, 1991; Hockley \& Consoli, 1999).

The discrepancies arising between these previous studies might be related to the different methods of measuring memory performance or to differences in the delay periods that were examined (we discuss both of these possibilities in more detail after presenting the present results). In most of the previous studies, forgetting rates were examined across very long retention intervals that varied up to several weeks. Importantly, Eichenbaum et al. (1994) proposed that at short retention intervals, familiarity would decrease more rapidly than recollection. However, as the delay between study and test increases, the slopes of the two forgetting functions should converge. Thus, only at short retention intervals is the forgetting rate of familiarity expected to be steeper than that associated with recollection.

In the present study, we examined the forgetting rates over short retention intervals in healthy human subjects using a continuous recognition test procedure. The subjects were presented with a list of words to remember. Intermixed in the list were memory test words, some of which were repeated from earlier in the list. The studytest lag (i.e., the difference between the study position and the test position of the item in the list) varied between 1 and 32 items.

In order to assess recollection, we examined the subjects' ability to retrieve an arbitrary association formed during the study event. That is, each study item was presented in either red or green letters, and recollection was 
measured as the ability to accurately remember the color of the studied word. We assumed that if a subject was able to accurately determine the color of the item, he or she must have recollected some qualitative information about the study event because assessing the familiarity of the item should not provide the associative information necessary to support accurate color memory judgments.

Half of the study words were presented in red, and half were presented in green, and the subjects were instructed to try to remember each word and the color in which each word was presented by forming an association between the word and the color. The test words were presented in white letters, and for half of the items, the subjects were asked whether the item was studied in green. If the item was studied in green (i.e., target item) and the subject recollected that it was studied in green, the response should be yes. In contrast, if the item was studied in red (i.e., lure item) and the subject recollected this, the response should be no. Thus, the difference between the probability of responding "yes" to a target item, and the probability of responding "yes" to a lure item provided an index of the subject's ability to recollect the study color of the item. For example, if a subject had perfect memory for the color-word associations (i.e., the probability of recollection was 1.0), he or she would respond "yes" to all the target items and respond "no" to all the lure items. In contrast, if the subject had no color-word memory (i.e., the probability of recollection was 0 ), there should be no difference in the probability of responding "yes" to target or lure items.

In order to avoid introducing any bias toward preferentially encoding either the red or green items, for half of the test trials, the subjects were asked whether the item was green and for the other half, they were asked whether it was red. Moreover, to ensure that the subjects used familiarity as a basis for recognition responses, they were instructed to respond "yes" to all items that were familiar but not recollected. Thus, if they encountered an item that they were sure was studied but for which they could not recollect the study color, they were to respond "yes."

If forgetting affects familiarity but not recollection, the ability to recollect the color of the items should remain constant as study-test lag increases, but the ability to recognize items as having been studied should decrease. That is, the probability of responding "yes" to studied items (both targets and lures) should decrease as the study-test lag increases (i.e., the items should become less familiar as more intervening items are presented), but the difference between performance for the target and lure items (i.e., their ability to determine the study color) should remain constant. In contrast, if both recollection and familiarity decrease across the study-test lag, the probability of responding "yes" to target and lure items should decrease, and the difference between performance on the target and lure items should also decrease.

The results were further analyzed by using the process dissociation procedure (Jacoby, 1991) in order to derive quantitative estimates of recollection and familiarity. Our main hypothesis could be tested without the use of the process dissociation estimates; however, acquiring such estimates facilitates more direct comparisons of the forgetting functions of recollection and familiarity. The estimates were derived as follows. The subjects were expected to respond "yes" to a target item (e.g., "yes" to a green item when asked "was it green?") if it was recollected $(\mathrm{R})$ or if it was familiar in the absence of recollection $[\mathrm{F}(1-\mathrm{R})]$. Thus, $P$ (“yes"|target) $=\mathrm{R}+\mathrm{F}(1-$ $\mathrm{R})$. In contrast, they should respond "yes" to a lure item (e.g., "yes" to a green item when asked "was it red?") only if it was familiar in the absence of recollection $[\mathrm{F}(1-\mathrm{R})]$. Thus, $P$ ("yes"|lure $)=\mathrm{F}(1-\mathrm{R})$. Recollection was estimated by subtracting the probability of responding "yes" to a lure item from the probability of responding "yes" to a target item $[\mathrm{R}+\mathrm{F}(1-\mathrm{R})-\mathrm{F}(1-\mathrm{R})=\mathrm{R}]$. Familiarity was then estimated as the probability of responding "yes" to a lure item given that it was not recollected $[P($ "yes"|target $) /(1-\mathrm{R})=\mathrm{F}]$.

Two separate experiments were conducted in order to verify that the results were replicable, but because the methods and results were so similar, they are described together.

\section{METHOD}

\section{Participants and Materials}

Sixteen and twenty-four undergraduate students participated in Experiments 1 and 2, respectively. Informed consent was obtained prior to testing, and the rights of the subjects were protected. Seven hundred medium-frequency words were used in Experiment 1, and 400 words were used in Experiment 2.

\section{Design and Procedure}

In Experiment 1, words were presented one at a time, in the center of a computer screen, in lowercase letters, and the subjects responded on the computer keyboard. The subjects were told that they would be presented with a continuous list of words that contained a mixture of study and test items. They were told that each study word would be presented in either red or green and that they were to remember each word and its color. To increase recognition performance on the test items, the subjects were instructed to try to make associations between the study items and the color in which they were presented (e.g., "if you were presented with the word mountain in red you might think of a volcano"). Each study item was presented for $2 \mathrm{sec}$ to allow the subjects time to form meaningful associations.

Test items were presented in white letters, along with either a "?red?" or a "?green?" prompt. The subjects were instructed to respond "yes" if the word was presented in the color indicated by the prompt. If the subject remembered that the word had been presented in the other color, or if the word had not been studied, they were to respond "no." Furthermore, they were instructed that if they thought the item had been studied, but they could not remember the study color they were to respond "yes." The test items remained on the screen until the subject made a response.

The study list consisted of 1,000-item presentations, of which 700 were study words and 300 were test words. The test words were presented after a study-test lag (i.e., the difference between the study and test positions of the item) of either $1,2,4,8,16$, or 32 items. A lag of 1 indicates that the word was tested immediately after it had been studied. There were 40 items tested at each lag. Performance on the items tested at lags of 1,2 , and 4 were not analyzed because memory across these short lags likely reflects working memory, which is functionally distinct from the long-term memory components that were the focus of the present study (see Eichenbaum et al., 1994). The subjects in the present experiments generally performed 
perfectly at these short lags, indicating that they understood the test instructions. For each lag condition, half the items (20) were studied in green. Half of these (10) were tested with a "?green?" prompt, whereas the other half were tested with a "?red?" prompt. The other 20 items at each condition were studied in red. Half of these were tested with a "?red?" prompt, whereas the other half were tested with a "?green?" prompt. The remaining 60 test words were new items that had not been studied previously. Half of these were tested with a "red?" prompt, and half were tested with a "?green?" prompt.

The design and procedure used in Experiment 2 were similar to those used in Experiment 1, with the following exceptions. The study and test words were presented in uppercase letters. There were 592 trials that included four different lag conditions (48 items each in each lag condition of $2,8,16$, and 32 ), and 48 new test items.

\section{RESULTS}

The upper panels in Figure 1 illustrate the proportion of target, lure, and new items receiving yes responses across the critical study-test lags of 8, 16, and 32 items. Performance was collapsed across the red and green conditions because this factor did not influence performance. Thus, the scores for the target items represent the probability of responding yes during a "?red?" test prompt to an item that was red at study, or responding "yes" during a "?green?" test prompt to an item that was green at study. The scores for the lure items represent the probability of responding "yes" during a "?red?" test prompt to an item that was green during study, or responding "yes" during a "?green?" test prompt to an item that was red during study.
As lag increased, recognition memory (i.e., the probability of a yes response) for the target and lure items decreased [Experiment $1, F(2,30)=4.14, p<.05$; Experiment $2, F(2,44)=29.00, p<.001]$, showing that there was significant forgetting across study-test lag. Thus, some recognition memory process was influenced by study-test lag. Importantly, performance on the target and lure items decreased in parallel (i.e., the lag $\times$ test condition interaction did not approach significance; $F_{\mathrm{S}}<1.1$ for Experiments 1 and 2), indicating that the ability to remember the color of the studied items did not change as study-test lag increased. The constant rate of recollection in the context of a significant decrease in recognition performance suggests that forgetting selectively affected familiarity.

To directly contrast recognition memory and color memory, we derived estimates of recognition and color memory discrimination using signal detection theory (see Macmillan \& Creelman, 1991). For recognition memory, $d^{\prime}$ was calculated by using the proportion of studied items and new items that elicited a yes response as hits and false alarms, respectively. For color memory, $d^{\prime}$ was calculated by using the proportion of target study words and nontarget study words eliciting a yes response as hits and false alarms. The analysis indicated that lag interacted with the type of memory discrimination. The interaction did not quite reach significance for Experiment $1[F(2,30)=1.577$, $p=.223]$ but was significant in Experiment $2[F(2,48)=$ $5.135, p<.01]$, indicating that the study-test lag had sig-
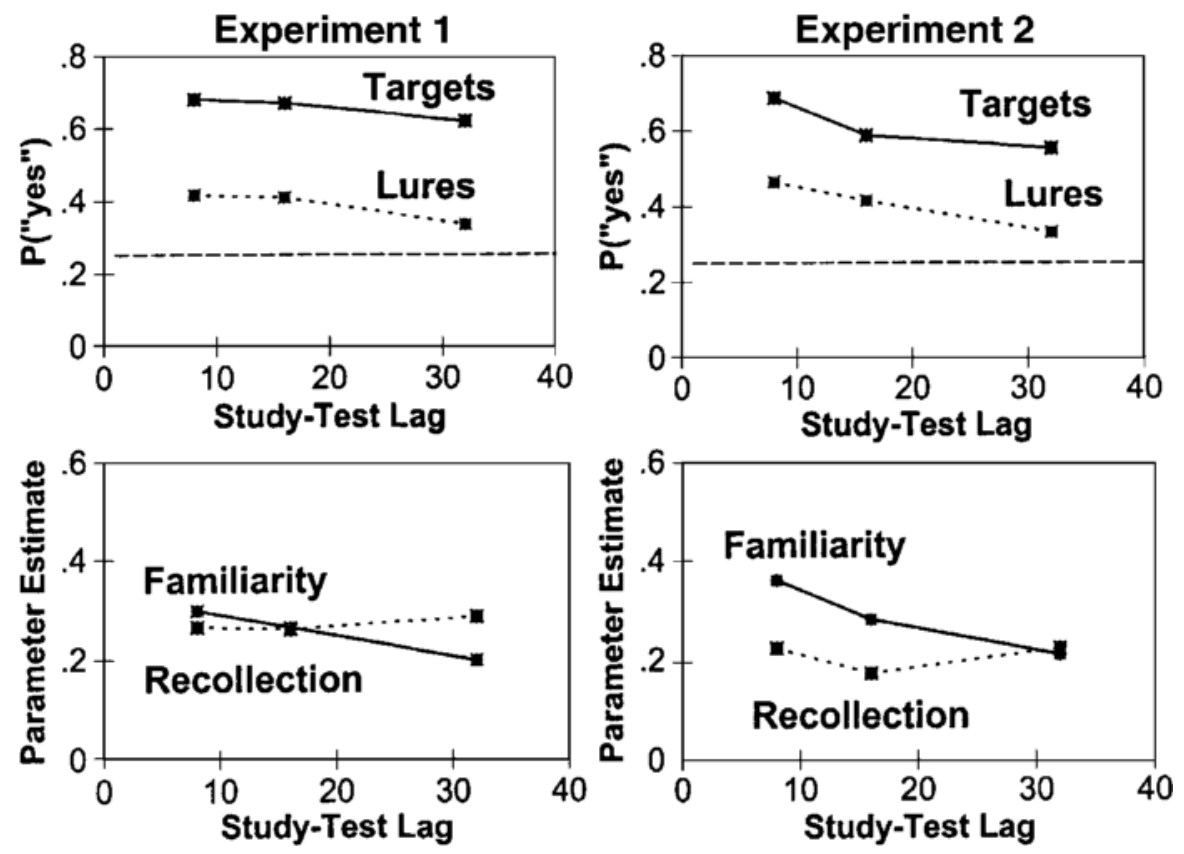

Figure 1. Top panels: Recognition memory performance for target and lure items plotted as a function of study-test lag. The average probability of incorrectly accepting a new item is presented as a horizontal dashed line. Bottom panels: Estimates of recollection and familiarity derived using the process dissociation procedure plotted as a function of study-test lag. To account for false recognitions of new items, the probability of incorrectly accepting new items was subtracted from the familiarity estimates. 
nificantly different effects on recognition memory and color memory. In order to determine whether this pattern of results was dependent on the signal detection-based index of discriminability, a subsequent analysis was conducted in which hits minus false alarms was used as an index of discriminability, but it led to the same pattern of results.

The results were analyzed further by using the process dissociation procedure (Jacoby, 1991) to derive quantitative estimates of recollection and familiarity (as described earlier). An examination of the average parameter estimates (see lower panels in Figure 1) indicates that studytest lag led to a crossover interaction between recollection and familiarity. As study-test lag increased, recollection estimates remained constant $(F \mathrm{~s}<1.1$ for Experiments 1 and 2), whereas familiarity estimates decreased significantly [Experiment $1, F(2,30)=4.351, p<.05$; Experiment $2, F(2,44)=18.856, p<.001]$. A subsequent analysis directly compared recollection and familiarity estimates and showed that lag interacted with the two processes (i.e., the interaction was marginally significant for Experiment $1[F(2,30)=2.58, p=.092]$ and was significant in Experiment $2[F(2,44)=5.219, p<.01])$, indicating that study-test lag differentially influenced recollection and familiarity.

\section{DISCUSSION}

The results showed that familiarity was more susceptible to forgetting than was recollection over study-test lags ranging from 8 to 32 items. The ability to recognize previously presented words decreased as study-test lag increased, whereas the ability remember the color of the words was not influenced by study-test lag. The observed dissociation was predicted on the basis of a model of medial temporal lobe function (i.e., Eichenbaum et al., 1994) in which it is proposed that the parahippocampal-basedresponses reflect an intermediate term storage process that exhibits faster forgetting across short retention intervals than does hippocampal-based responses. Although that model is based primarily on results from single-cell recording studies and lesion studies of animals, the present results indicate that it is useful in generating accurate predictions about human memory performance in a task that required recollection and familiarity. These results highlight a fundamental parallel between the memory theories based on these different species and indicate that the differential forgetting rates of recollection and familiarity that are observed in nonhuman species generalize to human subjects.

As mentioned earlier, previous cognitive studies have led to conflicting results regarding the forgetting rates of recollection and familiarity in humans. However, a careful consideration of those results along with a consideration of the model of Eichenbaum et al. (1994) suggests that those discrepancies are only apparent. Eichenbaum et al. proposed that at short retention intervals familiarity would decrease more rapidly than recollection, but as the delay between study and test increases, the slopes of the two forgetting functions should converge. In the present study, forgetting was examined at short intervals, ranging from 8 to 32 items, and it was found that familiarity did decrease more rapidly than did recollection. Over similar lags, single-item recognition was found to decrease, whereas word-pair association memory was found to remain constant (Hockley, 1991). Similar forgetting functions were also found for word-pair and singleword recognition in a study-test block design (Hockley, 1991), indicating that the pattern was not restricted to continuous study-test procedures. Thus, over short retention intervals when recollection is measured as memory for color, as in the present experiments, or as word-word associations, as in the associative recognition studies, recollection does appear to be less susceptible to forgetting than does familiarity.

However, when performance is examined over longer retention intervals, both recollection and familiarity appear to decrease together. For example, when forgetting was measured across delays extending up to 7 days, both item and association memory were found to decrease together (Hockley \& Consoli, 1999). Similarly, over a period of 7 days, source memory and item memory were found to decrease at similar rates (Bornstein \& LeCompte, 1995). As mentioned earlier, remember-know studies have led to a rather complex pattern of results. Recollection generally decreased over time, although different studies showed different effects on know responses (i.e., they either remained constant, decreased, or increased significantly over time). The proportion of know responses, however, is mathematically constrained by the proportion of remember responses, because subjects are instructed to respond "know" only if the item was not recollected. Thus, know responses cannot be used as an index of familiarity. However, if familiarity is estimated as the probability of a know response given that the subject had the opportunity to make a know response (i.e., the item was familiar and not recollected: $F=K /(1-R)$; see Yonelinas \& Jacoby, 1995), the results from the remember-know studies (e.g., Gardiner, 1988; Gardiner \& Java, 1991; Hockley \& Consoli, 1999) are consistent in showing that recollection and familiarity exhibit similar rates of forgetting. Importantly, in these remember-know studies, forgetting was examined across long delays, thus, they are consistent with the general pattern that at longer retention intervals both processes exhibit roughly equivalent rates of forgetting, but at short retention intervals, familiarity decreases more rapidly than does recollection. The only study that does not conform to this pattern of results is a study by Mandler et al. (1969), in which it was suggested that familiarity decreased faster than recollection, even over long retention intervals. Why this study is in disagreement with the others is not clear; however, it may be that the method used to measure recollection in that study (i.e., a correlation with list organization) does not index the same process that is measured with the other test procedures.

The process dissociation procedure has been used to measure the forgetting rates of processes that support per- 
formance in other types of memory tests such as word stem cued recall (Jacoby, Kelley, Brown, \& Jasechko, 1989; Mayes, 1995; McBride \& Dosher, 1999; SchmitterEdgecombe, 1999). An important question for future research is to determine how recollection and familiarity are related to the processes that support performance on these other types of memory tasks. The results from animal studies do not support any strong predictions in this case because the relevant studies with animals have been limited primarily to tests of recognition memory rather than cued recall. However, some cognitive models suggest that the recollection and familiarity processes that support recognition memory also support performance on tasks like stem completion (e.g., Mandler, 1980), thus one might expect to see comparable forgetting rates across these tasks. However, a number of studies have indicated that the processes that support performance on recognition memory tests are functionally distinct from those supporting performance on these other types of memory tests (e.g., Hamann \& Squire, 1997; Jacoby, 1991; Wagner, Gabrieli, \& Verfaellie, 1997), thus it is possible that forgetting rates in different tests might be quite different.

The results of the process dissociation procedure were in agreement with the initial analysis of the recognition and color memory performance. The advantages and disadvantages of the process dissociation procedure have been discussed extensively elsewhere (e.g., Cowan, 1996; Curran \& Hintzman, 1997; Erdfelder \& Buchner, 1998; Jacoby, 1998; Jacoby, Begg, \& Toth, 1997; Jacoby \& Shrout, 1997; Jacoby, Yonelinas, \& Jennings, 1997; Russo, Cullis, \& Parkin, 1998; Wainwright \& Reingold, 1996; Yonelinas \& Jacoby, 1996b). However, one important assumption underlying the procedure is that recollection and familiarity independently contribute to recognition memory. The independence assumption is supported by findings that recollection and familiarity are related to independent electrophysiological components (e.g., Curran, 2000; Düzel et al., 1997) and by behavioral studies showing that the two processes can be doubly dissociated (see Yonelinas 1994; Yonelinas \& Jacoby, 1994). If the two processes were dependent, such dissociations should not be possible.

The present experiments indicated that recollection and familiarity exhibit distinct forgetting functions, and thus the results are consistent with the assumption that recollection and familiarity reflect independent recognition processes. Nonetheless, it is important to note that the main conclusions derived from the process dissociation analysis in the present experiments would be the same, even if the two processes were assumed to be dependent. For example, if the two processes were perfectly correlated (e.g., all of the recollected items were also accepted as old on the basis of familiarity), familiarity would be estimated as the overall recognition performance for target items (i.e., all the recollected items plus the items that were familiar and not recollected). Because recognition performance decreased across study-test lag, it would follow that familiarity must also have decreased across study-test lag. Moreover, by the redundancy assumption, recollection would still be estimated as the ability to determine word color, and thus it would follow that lag did not influence recollection.

A potential limitation associated with a direct examination of forgetting rates is that differences in forgetting can be caused by differences in the level of performance. In the present study, the ability to recognize items was greater than the ability to recollect the item color. Thus, this dissociation could be due to scaling differences. However, two observations argue against a scaling explanation of these forgetting differences. First, the estimates of recollection and familiarity were found to form a significant crossover interaction, indicating that the recollection and familiarity were differentially affected by lag, yet they were at comparable points on the scale. Second, Hockley (1991) found that word pair recognition decreased significantly faster than item recognition, even when performance levels were comparable. That is, he observed a significant crossover interaction in associative and item recognition accuracy scores. It is unlikely that scaling effects could have been responsible for these crossover interactions.

In the present study, it is likely that the subjects recollected other qualitative information regarding the study events besides that which would be useful for the required color discrimination. This has been referred to as noncriterial recollection (Yonelinas \& Jacoby, 1996a) For example, they might have recollected some aspect about the presentation of the word but were unable to recollect the study color. Given that recollection was measured as the probability of accurately remembering the color of a study item, the derived recollection estimates might underestimate recollection owing to the fact that not all recollected information may be useful for that discrimination. This could lead the familiarity estimates to overestimate true familiarity, since these items would influence performance but would not be measured as recollection (for a further discussion of this issue, see Gruppuso, Lindsay, \& Kelley, 1997; Mulligan \& Hirshman, 1997; Wagner et al., 1997; Yonelinas \& Jacoby, 1996a). However, most important for the present study, this could not have caused the observed dissociation in forgetting rates between recollection and familiarity; rather, the presence of some recollection in our familiarity estimates would have forced familiarity and recollection to behave in similar manners. Thus, to the extent that this form of recollection occurred, it would have made it more difficult to observe the dissociation between recollection and familiarity.

Another way of describing recollection and familiarity (see Yonelinas \& Jacoby, 1995) is to argue that they simply reflect criterial recollection (e.g., color memory) and noncriterial recollection (e.g., memory for everything else). The problem with such an account is that it leaves unexplained why some manipulations, such as study-test lag, selectively influence noncriterial recollection, whereas other manipulations (e.g., response deadline, aging, and divided attention at test) have the opposite effects (e.g., see Gruppuso et al., 1997; Jennings \& Ja- 
coby, 1993; Yonelinas \& Jacoby, 1994). Moreover, it does little to explain why these two types of memory are associated with distinct neuroanatomical and electrophysiological correlates (e.g., Curran, 2000; Düzel et al., 1997; Eldridge et al., 2000; Gabrieli et al., 1997; Henson et al., 1999; Klimesch et al., 2001; Smith, 1993; Yonelinas et al., 2001). Whether one chooses to use the terms recollection and familiarity is not particularly important. However, it is important to realize that there are two functionally and neuroanatomically distinct types of memory that contribute to recognition performance.

Another method that has been used to measure the two processes underlying recognition memory is the remember-know procedure. Preliminary studies conducted in our lab, however, indicated that it is difficult to apply this method in the continuous study-test lag paradigm. The problem was that subjects were often unsure as to whether to respond "remember" or "know" to items in the lag experiment. It appeared to be very difficult for subjects to discriminate between the experiences of remembering and knowing when very short study-test intervals were used. This may be due in part to the fact that differences in familiarity associated with items from the different lag conditions provided subjects with very useful information about the temporal context in which the item was presented. For example, an item may be experienced as so familiar that it must have been presented only a few items ago. If the subject knows when the item was presented, it is not the case that they simply know that it was studied. On the other hand, because they may be unable to retrieve any other qualitative information about the study event, it is not the case that they truly remember the study event either. Previous studies have indicated that the results of the remember-know procedure converge with those from other methods like the process dissociation procedure (e.g., Yonelinas, 2001; Yonelinas \& Jacoby, 1995); however, the continuous study-test lag paradigm might reflect one set of conditions in which the two procedures are not interchangeable.

An obvious question for future studies is whether the neuroanatomical substrates of recollection and familiarity in humans are similar to those identified in animal studies. A number of recent studies have been consistent with the animal studies in suggesting that recollection relies on the hippocampal region and that familiarity may be supported by other temporal lobe regions. For example, hippocampal activation is associated with recollection, but not familiarity-based recognition responses (e.g., Eldridge et al., 2000; Gabrieli et al., 1997; Henson et al., 1999; Yonelinas et al., 2001). Moreover, although patients with combined hippocampal and parahippocampal damage exhibit deficits in both recollection and familiarity (e.g., Yonelinas et al., 1998), patients with selective hippocampal damage exhibit disproportionate deficits on tests that require recollection, as compared with tasks that can be based on familiarity (e.g., Aggleton \& Shaw, 1996). Studies that further explore the functional characteristics and the neuroanatomical substrates of recollec- tion and familiarity in human and nonhuman species will be essential in developing more complete models of memory retrieval.

\section{REFERENCES}

Aggleton, J. P., \& Brown, M. B. (1999). Episodic memory, amnesia and the hippocampal-anterior thalamic axis. Behavioral \& Brain Sciences, 22, 425-444.

Aggleton, J. P., \& Shaw, C. (1996). Amnesia and recognition memory: A re-analysis of psychometric data. Neuropsychologia, 34, 51-62.

At kinson, R. C., \& JuOla, J. F. (1974). Search and decision processes in recognition memory. In D. H. Krantz, R. C. Atkinson, R. D. Luce \& P. Suppes (Eds.), Contemporary developments in mathematical psychology: Vol. 1. Learning, memory and thinking (pp. 101-146). San Francisco: Freeman.

Bornstein, B. H., \& LeCompte, D. C. (1995). A comparison of item and source forgetting. Psychonomic Bulletin \& Review, 2, 254-259.

Brown, M. W., Wilson, F. A., \& Riches, I. P. (1987). Neuronal evidence that inferomedial temporal cortex is more important than hippocampus in certain processes underlying recognition memory. Brain Research, 409, 158-162.

Cowan, N. (1996). Can we resolve contradictions between process dissociation models? Consciousness \& Cognition: An International Journal, 5, 255-259.

Curran, T. (2000). Brain potentials of recollection and familiarity. Memory \& Cognition, 28, 923-938.

Curran, T., \& Hintzman, D. L. (1997). Consequences and causes of correlations in process dissociation. Journal of Experimental Psychology: Learning, Memory, \& Cognition, 23, 496-504.

Düzel, E., Yonelinas, A. P., Mangun, G. R., Heinze, H., \& TulVING, E. (1997). Event-related brain potential correlates of two states of conscious awareness in memory. Proceedings of the National Academy of Sciences, 94, 5973-5978.

Eichenbaum, H., \& Cohen, N. J. (1988). Representation in the hippocampus: What do hippocampal neurons code? Trends in Neurosciences, 6, 244-248.

Eichenbaum, H., Otto, T., \& Cohen, N. (1994). Two functional components of the hippocampal memory system. Behavioral \& Brain Sciences, 17, 449-518.

Eldridge, L. L., Knowlton, B. J., Furmanski, C. S., Bookheimer, S. Y., \& ENGEL, S. A. (2000). Remembering episodes: A selective role of the hippocampus during retrieval. Nature Neuroscience, 3, 1149-1152.

ERdFElder, E., \& Buchner, A. (1998). Process-dissociation measurement models: Threshold theory or detection theory? Journal of Experimental Psychology: General, 127, 83-97.

FAHY, F. L., RichES, I. P., \& BROWN, M. W. (1993). Neuronal activity related to visual recognition memory: Long-term memory and the encoding of recency and familiarity information in the primate anterior and medial inferior temporal and rhinal cortex. Experimental Brain Research, 96, 457-472.

Gabrieli, D. E., Brewer, J. B., Desmond, J. E., \& Glover, G. H. (1997). Separate neural bases of two fundamental memory processes in human medial temporal lobe. Science, 276, 264-266.

Gaffan, D., \& Murray, E. A. (1992). Monkeys (Macaca fascicularis) with rhinal cortex ablations succeed in object discrimination learning despite 24-hr intertrial intervals and fail at matching to sample despite double sample presentations. Behavioral Neuroscience, 106, 30-38.

GARDINER, J. M. (1988). Functional aspects of recollective experience. Memory \& Cognition, 16, 309-313.

GARDINER, J. M., \& JAVA, R I. (1991). Forgetting in recognition memory with and without recollective experience. Memory \& Cognition, 19, 617-623.

Gruppuso, V., Lindsay, D. S., \& Kelley, C. (1997). The processdissociation procedure and similarity: Defining and estimating recollection and familiarity in recognition memory. Journal of Experimental Psychology: Learning, Memory, \& Cognition, 23, 259-278.

Hamann, S. B., \& SQuire, L. R. (1997). Intact perceptual memory in the absence of conscious memory. Behavioral Neuroscience, 111, 850-854. Henson, R. N. A., Rugg, M. D., Shallice, T., Josephs, O., \& Dolan, 
R. J. (1999). Recollection and familiarity in recognition memory: An event-related functional magnetic resonance imaging study. Journal of Neuroscience, 19, 3962-3972.

HockLEY, W. E. (1991). Recognition memory for item and associative information: A comparison of forgetting rates. In W. E. Hockley \& S. Lewandowsky (Eds.), Relating theory and data: Essays on human memory in honor of Bennet B. Murdock (pp. 227-248). Hillsdale, NJ: Erlbaum.

Hockley, W. E., \& Consoli, A. (1999). Familiarity and recollection in item and associative recognition. Memory \& Cognition, 27, 657-664.

Huppert, F., \& Piercy, M. (1976). Recognition memory in amnesic patients: Effects of temporal context and familiarity of material. Cortex, 12, 3-20.

JACOBY, L. L. (1991). A process dissociation framework: Separating automatic from intentional uses of memory. Journal of Memory \& Language, 30, 513-541.

JАCOBY, L. L. (1998). Invariance in automatic influences of memory: Toward a user's guide for the process-dissociation procedure. Journal of Experimental Psychology: Learning, Memory, \& Cognition, 24, 3-26.

JACOBY, L. L., BEGG, I. M., \& ToTH, J. P. (1997). In defense of functional independence: Violations of assumptions underlying the processdissociation procedure? Journal of Experimental Psychology: Learning, Memory, \& Cognition, 23, 484-495.

JACOBY, L. L., \& DALlas, M. (1981). On the relationship between autobiographical memory and perceptual learning. Journal of Experimental Psychology: General, 110, 306-340.

Jacoby, L. L., Kelley, C., Brown, J., \& JaSechko, J. (1989). Becoming famous overnight: Limits on the ability to avoid unconscious influences of the past. Journal of Personality \& Social Psychology, 56, 326-338.

JACOBY, L. L., \& Shrout, P. E. (1997). Toward a psychometric analysis of violations of the independence assumption in process dissociation. Journal of Experimental Psychology: Learning, Memory, \& Cognition, 23, 505-510.

Jacoby, L. L., Yonelinas, A. P., \& Jennings, J. M. (1997). The relationship between conscious and unconscious (automatic influences): A declaration of independence. In J. D. Cohen \& J. W. Schooler (Eds.), Scientific approaches to consciousness: The 25th annual Carnegie Symposium on Cognition (pp. 13-47). Mahwah, NJ: Erlbaum.

JENNINGS, J. M., \& JACOBY, L. L. (1993). Automatic versus intentional uses of memory: Aging, attention, and control. Psychology \& Aging, 8, 283-293.

Klimesch, W., Doppelmayr, M., Yonelinas, A., Kroll, N. E. A., LaZZARA, M., Rohm, D., \& GRUBER, W. (2001). Theta synchronization during episodic retrieval: Neural correlates of conscious awareness. Cognitive Brain Research, 12, 33-38.

Macmillan, N. A., \& Creelman, C. D. (1991). Detection theory: A user's guide. New York: Cambridge University Press.

MandLeR, G. (1980). Recognizing: The judgment of previous occurrence. Psychological Review, 87, 252-271.

Mandler, G., Pearlstone, Z, \& Koopmans, H. J. (1969). Effects of organization and semantic similarity on recall and recognition. Journal of Verbal Learning \& Verbal Behavior, 8, 410-423.

Mayes, A. R. (1995). Memory and amnesia. Behavioural Brain Research, 66, 29-36.

McBride, D. M., \& Dosher, B. A. (1999). Forgetting rates are comparable in conscious and automatic memory: A process-dissociation study. Journal of Experimental Psychology: Learning, Memory, \& Cognition, 25, 583-607.

Mishkin, M., \& Murray, E. A. (1994). Stimulus recognition. Current Opinion in Neurobiology, 4, 200-206.

Mulligan, N. W., \& Hirshman, E. (1997). Measuring the basis of recognition memory: An investigation of the process-dissociation procedure. Journal of Experimental Psychology: Learning, Memory, \& Cognition, 23, 280-304.

O'KeEfe, J. (1976). Place units in the hippocampus of the freely moving rat. Experimental Neurology, 51, 78-109.

O'KeEFE, J., \& NADEL, L. (1978). The hippocampus as a cognitive map. Oxford: Oxford University Press, Clarendon Press.

RolLs, E. T. (1996). A theory of hippocampal function in memory. Hippocampus, 6, 601-620.

Russo, R., Cullis, A. M., \& Parkin, A. J. (1998). Consequences of violating the assumption of independence in the process dissociation procedure: A word fragment completion study. Memory \& Cognition, 26, 617-632.

Schmitter-Edgecombe, M. (1999). Effects of divided attention and time course on automatic and controlled components of memory in older adults. Psychology \& Aging, 14, 331-345.

SмIтH, M. E. (1993). Neurophysiological manifestations of recollective experience during recognition memory judgments. Journal of $\mathrm{Cog}$ nitive Neuroscience, $\mathbf{5}, 1-13$.

Tulving, E. (1985). Memory and consciousness. Canadian Psychologist, 26, 1-12.

Wagner, A. D., Gabrieli, J. D. E., \& Verfaellie, M. (1997). Dissociations between familiarity processes in explicit recognition and implicit perceptual memory. Journal of Experimental Psychology: Learning, Memory, \& Language, 23, 305-323.

Wainwright, M. J., \& ReIngold, E. M. (1996). Response bias correction in the process dissociation procedure: Approaches, assumptions, and evaluation. Consciousness \& Cognition: An International Journal, 5, 232-254.

YonelinAs, A. P. (1994). Receiver-operating characteristics in recognition memory: Evidence for a dual-process model. Journal of Experimental Psychology: Learning, Memory, \& Cognition, 20, 1341-1354.

Yonelinas, A.P. (2001). Consciousness, control and confidence: The three Cs of recognition memory. Journal of Experimental Psychology: General, 130, 361-379.

Yonelinas, A. P., Hopfinger, J. B., Buonocore, M. H. Kroll, N. E. A., \& BAYNES, K. (2001). Hippocampal, parahippocampal and occipitaltemporal contributions to associative and item recognition memory: An fMRI study. NeuroReport, 12, 359-363.

Yonelinas, A. P., \& JACOBY, L. L. (1994). Dissociation of processes in recognition memory: Effects of interference and of test speed. Canadian Journal of Experimental Psychology, 48, 516-534.

Yonelinas, A. P., \& JACOBY, L. L. (1995). The relation between remembering and knowing as bases for recognition: Effects of size congruency. Journal of Memory \& Language, 34, 622-643.

Yonelinas, A. P., \& JACOBY, L. L. (1996a). Noncriterial recollection: Familiarity as automatic, irrelevant recollection. Consciousness \& Cognition, 5, 131-141.

Yonelinas, A. P., \& JACOBY, L. L. (1996b). Response bias and the process dissociation procedure. Journal of Experimental Psychology: General, 4, 422-434.

Yonelinas, A. P., Kroll, N. E. A., Dobbins, I. G., Lazzara, M., \& KNIGHT, R. T. (1998). Recollection and familiarity deficits in amnesia: Convergence of remember/know, process dissociation, and ROC data. Neuropsychology, 12, 323-339.

Zola, S. M., Squire, L. R., Teng, E., Stefanacci, L., Buffalo, E. A., \& ClARK, R. E (2000). Impaired recognition memory in monkeys after damage limited to the hippocampal region. Journal of Neuroscience, 20, 451-463.

(Manuscript received July 14, 2000; revision accepted for publication September 19, 2001.) 